\title{
A NEW MODEL FOR INTEGRATED COMPUTING SCIENCE UNDERGRADUATE EDUCATION
}

\author{
Richard F. Paweska \\ Computing Science Department \\ The University College of the Cariboo \\ Canada
}

\begin{abstract}
With over 50 years of Computer Science in existence, a great effort has been spent on designing the best curricula for educating computer scientists (Tucker and Barnes 1991), educating computing professionals, as well as educating users of computers. In spite of this, there has not been in evidence an approach to creating a flexible university environment, which will support a flow between those three basic and different types of computing education.
\end{abstract}

This paper presents a model of integrated computing education which allows for: obtaining different levels of computing knowledge and proficiency, fast and flexible upgradability of computing skills, adding computing knowledge and skills to knowledge already possessed in another discipline. Finally the model recognises the value of Prior Learning Professional Experience (PLPE) as a factor in computing education.

\section{INTRODUCTION}

There has never been in the history of science an invention like the computer. Four characteristics of this phenomenon make it different from other inventions that revolutionised the behaviour of society in the past:

1 high penetration (computer components are now incorporated in nearly all other devices, trades, or concepts);

2 rapid change in sophistication of the computer hardware and software. New generations of tools appear when the previous tool has not yet been mastered by an overwhelming percentage of users;

3 high sophistication of the computing tools combined with a very easy access to these tools by the users;

4 wide range of universal software packages (tools) designed with the goal to satisfy a wide range of user .

These four elements determine an environment in which designing a flexible and universal model of computing education is a very difficult task. A team of faculty in the Computing Science department at the University College of the Cariboo has been experimenting over the last seven years with different approaches to solving this problem. The proposed model (UCC 1996, 1997) is presented in this paper. 


\section{CURRENT MODEL}

The current model of computing education divides all students into five categories.

1 Computer researchers (including cross-disciplinary programs): undergraduate and graduate computer science programs. The curricula for these programs are well designed and tested over the years. Use of the knowledge-based units (ACM 1991) allows easy comparison of different programs and their compatibility.

2 Computer professionals (diploma and undergraduate technical programs). The curricula for these programs are more designed on current skill demand then on creating a self-developing computer specialist.

3 Intelligent computer users (programs where the computer's role is so essential to the discipline that students in these programs have to obtain specific professional computing knowledge and computing skills). The curricula for these programs are developed in many different ways from combined programs (as 'Computer Science \& Statistics' (University of Toronto 1997)) to creating a special centres (or laboratories) for a specific application (as 'Environmental Information Engineering Program' at Keio University (Notkin and Schlichting 1993)).

4 Other computer users. For all other computer users the curriculum has traditionally been designed (until recently) by computer scientists and tends to focus on programming with elements of general problem solving. The use of knowledge acquired by students following these curricula was generally irrelevant to the real computing skills needed in their professional areas. Recent observation indicates that the pendulum is swinging to the other side. The members of a given profession are preparing computing curricula for their student (masking them often by including them as part of their other courses). Nearly all of these curricula tend to be designed to give students currently required computing skills only, instead of giving them the necessary knowledge and ability to master any new professional computing tools in a short period of time. This approach is shortsighted, especially with fast changing tools and the skills required to use them.

5 Computer illiterates who still outnumber all the groups listed above.

For each of these categories the computing education is designed separately and, in my opinion, does not allow for any mix between them.

It means that any graduate of a computing-related diploma with a vast working experience or a professional with extensive practice but gained through a set of professional courses has to take a full 3 or 4 year academic program to obtain a Bachelors degree. Similarly many graduates of academic computing programs have to attend special certification courses (or programs) to be allowed access to some professional positions (as LAN Administrators). 
It is only recently that some new initiatives are making headway in the computing education model. They are:

1 recognition of one's professional experience through Prior Learning Assessment (PLA);

2 recognition of education possessed by a candidate as a whole not by a course by course matching, known now as a block transfer of credits;

3 laddering or bridging curricula, custom designed to incorporate a candidate's knowledge and skills into a computing academic program;

4 recognition of credits for Web based courses.

Summary of the current model:

1 clearly visible separation of goals between all levels of professional and academic programs;

2 difficulty in transfer between programs or laddering from lower level programs to higher level (certificate, diploma, associate degree, baccalaureate);

3 difficulty in upgrading of knowledge and skills by existing barriers between programs of different types.

\section{PROPOSED MODEL}

The new model designed at the University College of the Cariboo integrates a majority of computing curricula into a one very flexible system, which includes the following.

1 An 'Introductory Information Technology' course compulsory for all students (currently only for science programs) which gives all students exposure to a variety of computing tools. The approach is modular allowing for fast modification of the course curricula and custom design for a variety of science programs [Appendix 1].

2 Diploma program in 'Computer Systems: Operations and Management' (CSOM) designed to produce low and middle level computing professionals [Appendix 2]. Students in this program are exposed to hands-on experience in a co-operative education program.

3 Bachelor of Technology in 'Applied Computing Science' (BT/ACS) [Appendix 3]. This is a two-year program $\left(3^{\text {rd }}\right.$ and $4^{\text {th }}$ year level) which is designed to produce computing professionals with a breadth similar to the academic computing graduates but with a clear emphasis on obtaining practical skills with the newest hardware and software available on the market. This emphasis is achieved by dividing some key courses such as 'Operating Systems' or 'Computer Networks' into two interdependent (sub) courses: one addressing fundamental principles (usually two credits) and the second addressing current implementation (usually one credit). The review of the implementation course is scheduled annually while the principle 
course will be reviewed each 3 to 5 years. This approach supports two other features implemented in the BT/ACS program.

- Renewal of knowledge. Each graduate of BT/ACS can return for a short period of time to upgrade his/her knowledge only in this implementation courses where changes were substantial or which are needed for his/or her current career change or advancement.

- Advanced Certificates. Graduates from other areas (science, arts, education...) with a proper academic breadth can join the BT/ACS program to obtain an Advanced Certificate within a year. Currently three such certificates are offered: 'Database Systems', 'Computer Networks', and 'Software Engineering'.

4 Computing Major in the 'Bachelor of Science Program' at UCC. This is a typical computing science program but with one exception: it allows laddering from any other program. [Appendix 4]

BT/ACS program is a cornerstone of our integrated model with three categories of entry:

entry from CSOM (or similar computing diploma program);

entry from Arts, Business, Education, Engineering, and Science;

professional entry.

The main features of the model are as follows.

- Standardisation of all students' basic computer skills by a modular introductory course.

- Wide area of entry into professional programs.

- Three levels of professional education: Diploma, Advanced Certificate, and Baccalaureate with easy laddering up.

- Standard academic computing program (Major and Minor) with laddering options from professional programs.

- Easy transfer between programs with custom designed bridging courses.

- Keeping up with technological changes due to incorporating two types of (sub) courses: 1. principles, 2. implementation.

- $\quad$ Easy upgrade of skills with implementation (sub) courses.

\section{CONCLUSION}

The proposed model was fully implemented in September 1997 (with the exception of Computing Major option to be implemented in September 1998) and already the interest in the proposed model's options is overwhelming.

1 Of 18 students admitted to the BT/ACS pilot program over half are recent or former CSOM or similar diploma program graduates, one quarter are students who completed two years of a Science program, and the reminder are professionals with limited academic background or graduates from undergraduate or graduate programs in other disciplines (including one BT/ACS student with a PhD). 
2 While the 'Science Introductory Computing Course' has been included as a compulsory course for all student in the Bachelor of Science Program (all options), in the first edition of the course over $10 \%$ of the registered students come from Arts and Education.

3 The CSOM Program has obtained a considerable boost by providing a laddering to obtaining a Computing Degree.

4 The Computing Major Option in the Bachelor of Science program may be used as a means of obtaining credentials for R\&D type of work and graduate studies.

\section{REFERENCES}

ACM (1991) ACM/IEEE-CS Joint Curriculum Task Force, Computing Curricula 1991, ACM.

Notkin, D. and Schlichting, R. D. (1993) Computer Science in Japanese Universities, IEEE Computer, May 1993.

Tucker, A. B. and Barnes, B. H. (1991) Flexible design: a summary of computing curricula 1991. IEEE Computer, November 1991.

UCC (1996) Bachelor of Technology in Applied Computing Science Program at UCC, Computing Science Department, UCC, 1996.

UCC (1997) Computing Science Major in B.Sc. Program at UCC, CS Department, UCC, 1997. University of Toronto (1997) Faculty of Arts and Science Calendar, Toronto.

\section{Appendix 1. Science Introductory Course (introductory level)}

An Information Technology Course which is compulsory for all students (currently only for Science Programs) gives all students exposure to a variety of computing tools. The approach is modular which allows fast modification of the course curriculum and custom design for a variety of Science programs.

Course objectives

The main objective is to provide students with an introduction to the 'computer world' which will enhance their ability to use computer resources in everyday work. This introduction provides basic computer knowledge that any graduate of a BSc Program should have to be competitive in the modern market place.

During the course students should:

1 acquire an understanding of the computer as a collection of resources (local and distributed) and its relevance and usefulness to student work;

2 acquire the understanding and practical ability to search for the resources needed globally on networks and locally on his/her computer system; 
3 be introduced to the computer as a system that facilitates sharing of resources, which allows multi-person projects to be efficiently scheduled and coordinated;

4 be exposed to basic methods and tools provided by computer systems and incorporate those methods and tools at work;

5 obtain the computer knowledge and confidence allowing them to keep pace with the changes in information technology.

Course Vectoring: $\quad(3,0,2)$

Course Outline

Module 1. Computer Resources

- The Computer System as a Collection of Resources

- $\quad$ Access to Resources

Module 2. Searching for and Sharing the Resources

- Computer Networks: Linking with other computers and sharing of the data.

- Search for resources (information and tools) on the Global Networks (Internet).

- Designing and implementing a www page.

Module 3. Working in an Integrated Environment

- Basic Components of an Integrated Office. Sharing and Exchange of Data between Components. Integrating Data.

- Projects: Organising, Scheduling, and Supervision of multi-person projects.

Module 4. Multimedia

- $\quad$ Presentations: Creating a presentation using a Multimedia Tools.

- Translating technical information into "audience friendly" Language.

Module 5. Analytical Tools

- Mathematical Analysis Package

- Models, Modelling and Simulation

Module 6. Advanced

- Objects, Properties, Events and Functions

- Visual Programming

\section{Appendix 2. Computer Systems: Operations and Management (CSOM) (diploma program)}

The CSOM Program is a two year diploma program and is designated to produce graduates who will immediately become productive employees, and who will have the breadth and background necessary for advancement as their career progresses. The main emphasis of the program is to highlight the importance of sound problem solving methodology, supported by hands on instructions in the most utilised computing software and hardware.

The program is supplemented by co-operative education option, which allow the majority of the CSOM students to integrate theory and practical experience during their study.

Graduation Requirements: 20 courses -60 credits consisting of: 
- 3 courses in Business, Accounting and Management;

- 2 courses in English;

- 2 courses in Mathematics and Statistics;

- 13 computing courses.

\section{Appendix 3. Bachelor of Technology in Applied Computer Science (BT/ACS)}

It is a two year program $\left(3^{\text {rd }}\right.$ and $4^{\text {th }}$ year level) which is designed to produce computing professionals with a breadth similar to the academic computing graduates but with clear emphasis on obtaining practical skills with the newest hardware and software available on the market. This emphasis is achieved by dividing some key courses, such as Operating Systems or Computer Networks into two interdependent (sub) courses: one addressing fundamental principles (usually two credits) and the second addressing current implementation (usually one credit). A review of the implementation course is scheduled annually while a principles course will be reviewed each 3 to 5 years. This approach supports currency of the material presented. Each graduate of BT/ACS can return for a short period of time to upgrade his/her knowledge only in this implementation courses where changes were substantial or which are needed for his/or her current career change or advancement.

Admission to BTACS Program occurs at the 3rd year level (or equivalent). Three categories of admission to the BTACS Program are possible:

- $\quad$ entry from CSOM Program at UCC (or equivalent computing diploma program) with minimum 2.33 GPA in computing courses;

- $\quad$ entry from Arts, Business, Education, Engineering, and Science with minimum 2.33 GPA;

- professional entry with a suitable combination of relevant work experience in the information technology field and post-secondary study, as determined by BTACS Co-ordinator (Program Advisor).

Admission requirements:

1. General Admission requirements

To be considered for admission to the BTACS Degree Program, students must have completed $60 \mathrm{UCC}$ credits (or equivalent) as follows:

1. Core requirements (30 credits):

- 4 computing courses: computer programming, computer organisation and data structures;

- 2 academic English courses;

- 4 from Math and Statistics (Calculus, Discrete Mathematics, Probability and Statistics.

2. Breadth Coverage (12 credits):

- 2 Science courses other than Computing or Mathematics;

- 2 courses in 2 different disciplines outside of Science, other than English.

3. Unspecified Lower level (18 credits): 
6 courses at the first year level or higher.

It is anticipated that students of varying background will not meet all of the BTACS Degree Program requirements. Course deficiencies must be completed prior to formal admittance to the BTACS Degree program, although conditional admittance will be allowed for students who have completed most of the admission requirements.

Co-operative Education Option

To support the professional side of the degree a co-operative work terms are available to students.

Program Requirements:

All BTACS Degree students must complete 20 courses (60 UCC credits) as listed below.

1 Core courses (7 UCC courses): Computer Networks (A \& B), Operating Systems (A \& B), Software Engineering, Web Site Design \& Programming, Database Systems Project I, Project II.

2 Computing Elective courses (8 UCC courses from the list of BTACS electives).

3 Business Elective courses (2 - 3 courses to be selected from the area of marketing, organisational behaviour and accounting).

4 Breadth Electives (2 - 3 courses to be selected from a non-computing Science area and approved by the Program Co-ordinator).

Example of Admission from CSOM Diploma program (Summary)

Graduates of UCC's CSOM Diploma program have 60 UCC credits. Following exemptions and admission requirements apply:

\begin{tabular}{|l|l|l|l|}
\hline $\begin{array}{l}\text { General Admission } \\
\text { Requirements }\end{array}$ & Exemptions & Requirements \\
\hline $\begin{array}{l}\text { Admission } \\
\text { Requirements } \\
\text { credits }\end{array}$ & 60 & 36 credits & 24 credits \\
\hline $\begin{array}{l}\text { Graduation } \\
\text { Requirements } \\
\text { credits }\end{array}$ & 18 credits & 42 credits \\
\hline $\begin{array}{l}\text { Total Length of the } \\
\text { study }\end{array}$ & 2 years plus \\
\hline
\end{tabular}

\section{Appendix 4. Computing Science Major Option in Bachelor of Science Program}

The CS Major in B.Sc. Program is a typical computing science program with one exception: it allows laddering from any other program. 
The Computing Science Program will follow the requirements for the new Bachelor of Science Program with specific computing requirements. Students will need 6 credits in Computing Science and 9 credits in Mathematics to enter the major. They will need 36 credits in computing courses at the 300 and 400 level as follow: 15 credits in core courses and 21 credits in computing electives selected from the list of 20 elective courses.

A Computing Science Major will enable students to pursue careers in all $\mathrm{R}$ $\& \mathrm{D}$ areas related to design and implementation of programming languages, system design and system organisation. The Major will provide the necessary qualifications for entering professional or graduate programs associated with computing science.

With the current impact of computers on all disciplines the Major will enable students to combine another discipline with computing science in the form of double majors. 